Review

\title{
Analysis of Immune Escape Variants from Antibody-Based Therapeutics against COVID-19: A Systematic Review
}

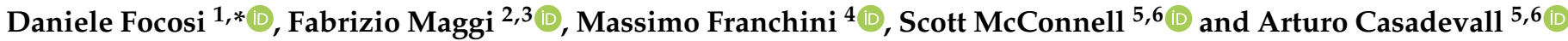 \\ 1 North-Western Tuscany Blood Bank, Pisa University Hospital, 56124 Pisa, Italy \\ 2 Department of Medicine and Surgery, University of Insubria, 21100 Varese, Italy; fabrizio.maggi63@gmail.com \\ 3 Laboratory of Microbiology, Azienda Socio Sanitaria Territoriale Sette Laghi, 21100 Varese, Italy \\ 4 Division of Transfusion Medicine, Carlo Poma Hospital, 46100 Mantua, Italy; \\ massimo.franchini@asst-mantova.it \\ 5 Department of Medicine, Johns Hopkins School of Public Health, Baltimore, MD 21218, USA; \\ smcconn8@jhu.edu (S.M.); acasade1@jhu.edu (A.C.) \\ 6 Department of Medicine, Johns Hopkins School of Medicine, Baltimore, MD 21218, USA \\ * Correspondence: daniele.focosi@gmail.com
}

check for

updates

Citation: Focosi, D.; Maggi, F.; Franchini, M.; McConnell, S.; Casadevall, A. Analysis of Immune Escape Variants from

Antibody-Based Therapeutics against COVID-19: A Systematic Review. Int J. Mol. Sci. 2022, 23, 29. https:// doi.org/10.3390/ijms23010029

Academic Editor: Franco Pandolfi

Received: 10 November 2021

Accepted: 17 December 2021

Published: 21 December 2021

Publisher's Note: MDPI stays neutral with regard to jurisdictional claims in published maps and institutional affiliations.

Copyright: (C) 2021 by the authors. Licensee MDPI, Basel, Switzerland. This article is an open access article distributed under the terms and conditions of the Creative Commons Attribution (CC BY) license (https:// creativecommons.org/licenses/by/ $4.0 /)$.

\begin{abstract}
The accelerated SARS-CoV-2 evolution under selective pressure by massive deployment of neutralizing antibody-based therapeutics is a concern with potentially severe implications for public health. We review here reports of documented immune escape after treatment with monoclonal antibodies and COVID-19-convalescent plasma (CCP). While the former is mainly associated with specific single amino acid mutations at residues within the receptor-binding domain (e.g., E484K/Q, Q493R, and S494P), a few cases of immune evasion after CCP were associated with recurrent deletions within the N-terminal domain of the spike protein (e.g., $\Delta$ HV69-70, $\Delta$ LGVY141-144 and $\Delta$ AL243-244). The continuous genomic monitoring of non-responders is needed to better understand immune escape frequencies and the fitness of emerging variants.
\end{abstract}

Keywords: SARS-CoV-2; COVID-19; convalescent plasma; viral clearance

\section{Introduction}

The SARS-CoV-2 spike protein is the target of neutralizing antibody (nAb)-based therapeutics. Control of the COVID-19 pandemic is being hampered by continued evolution of SARS-CoV-2, which includes mutations in the spike protein that can affect immunogenicity and antibody-mediated neutralization. Evolutionary modeling suggests that SARS-CoV-2 strains harboring 1-2 deleterious mutations naturally exist, and their frequency increases steeply under positive selection by monoclonal antibodies $(\mathrm{mAb})$ and vaccines [1]. In $2 \%$ of COVID cases, SARS-CoV-2 variants with multiple mutations occur, including in the spike glycoprotein, which can become the dominant strains in as little as one month of persistent in-patient virus replication [2]. While mutations can occur as a natural phenomenon of SARS-CoV-2 RNA replication and editing, the pace of mutagen emergence can also be affected by small-chemical antivirals (e.g., remdesivir [3] or molnupiravir [4]). Since antibody-based therapies targeting the spike protein would also put selective pressure on SARS-CoV-2, it is reasonable to assume that widespread deployment of $n A b$-based therapeutics could accelerate spike immune escape by selecting for variants that resist neutralization.

Mutations that confer in vitro resistance to therapeutic anti-spike mAbs have been characterized with various methods and are informative about treatment-emergent immune escape. Deep mutational scanning (DMS) predicts protein expression, ACE2 binding, and $\mathrm{mAb}$ binding [5]. The method was first deployed with yeast display libraries [6], then evolved to phage display libraries (https:/ /jbloomlab.github.io/SARS-CoV-2-RBD_MAP_ clinical_Abs/) [7] and finally mammalian cell surface display [8]. nAb binding is common within the fusion peptide and in the linker region before heptad repeat (HR) region 2. 
The complete escape maps forecast SARS-CoV-2 mutants emerging during treatment with $\mathrm{mAbs}$ and allow the design of escape-resistant $\mathrm{nAb}$ cocktails. A complete map of SARSCoV-2 RBD mutations that escape bamlanivimab and its cocktail with etesevimab has been generated $[9,10]$.

Although DMS was also applied to polyclonal antibodies in COVID-19-convalescent plasma (CCP) [11], the problem is much more complex, such that it is almost impossible to identify escape mutations in CCP or vaccinee-elicited sera, given the huge heterogeneity in antibody response among $\mathrm{CCP}$ donors and vaccinees, respectively. In vitro, continuous passaging of SARS-CoV-2 in the presence of a CCP unit with nAb titer $>1: 10^{4}$ led to $\triangle$ F140 spike mutation at day 45 , followed by E484K at day 73, and an insertion in the Nterminal domain (NTD): these accumulating mutations led to complete immune escape [12]. Similarly, K417N, E484K, and N501Y mutations were selected when pseudotyped SARS$\mathrm{CoV}-2$ was cultured in the presence of vaccine-elicited mAbs [13]. Although some have speculated that the large-scale use of CCP for COVID-19 could have played a role in the emergence of variants, there is no evidence for such an effect and the most likely explanation for the regular emergence of variants has been the huge number of affected individuals since each infection case provides a natural opportunity for variant creation [14].

In vivo, while intrahost-SARS-CoV-2 mutation development is typically very low [15], faster mutation rates (referred to as "accelerated evolution") have been found in longitudinal studies of immunodeficient patients who had persistent SARS-CoV-2 infections for several months and were treated with nAb-based therapeutics. In this study, we analyze and compare the available mutational data from SARS-CoV-2 under in vitro and in vivo selection and demonstrate that $\mathrm{mAb}$ and polyclonal (CCP) therapies elicit different types of mutational patterns.

\section{Materials and Methods}

We mined PubMed (which also indexes the bioRxiv and medrXiv preprint servers) for keywords related to COVID-19 ("COVID-19", "SARS-CoV-2"), immune escape ("immune escape", "treatment-emergent resistance") and nAb-based therapeutics ("convalescent plasma", "casirivimab", "imdevimab", "bamlanivimab", "etesevimab", "regdanvimab") both in vitro and in vivo. Clinical cases were annotated for eventual underlying immune deficiency, concurrent treatments and outcome. Figure 1 reports the study selection process according to PRISMA 2020 guidelines [16].

The 3D structural coordinates of the full spike protein (PDBID 6VXX; residues 27-1252) [16] and the receptor binding domain (PBDID 7BWJ; residues 319-529) [17], solved by cryoelectron microscopy and X-ray crystallography, respectively, were used to map mutational positions of interest. Mapping on the full spike was used to illustrate the diverse set of mutations throughout the spike glycoprotein, while the mutations localized to the RBD were illustrated using the more complete structural model obtained through crystallography. The mutations identified in each condition of in vivo or in vitro selection were tabulated and highlighted on the structures using color coding with PyMOL v.2.4.1. (Schrodinger, Mannheim, Germany) [18]. 

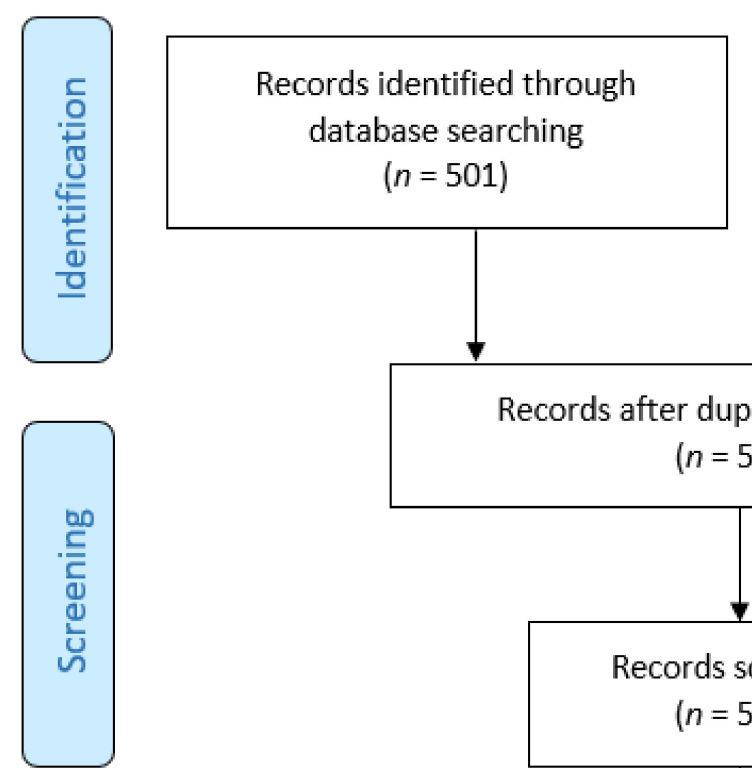

Records after duplicates removed

$$
(n=505)
$$
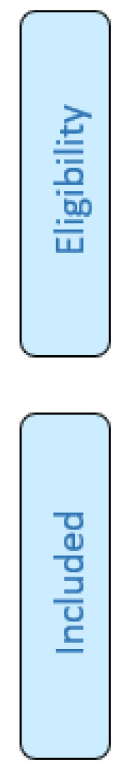

Additional records identified through other sources $(n=26)$

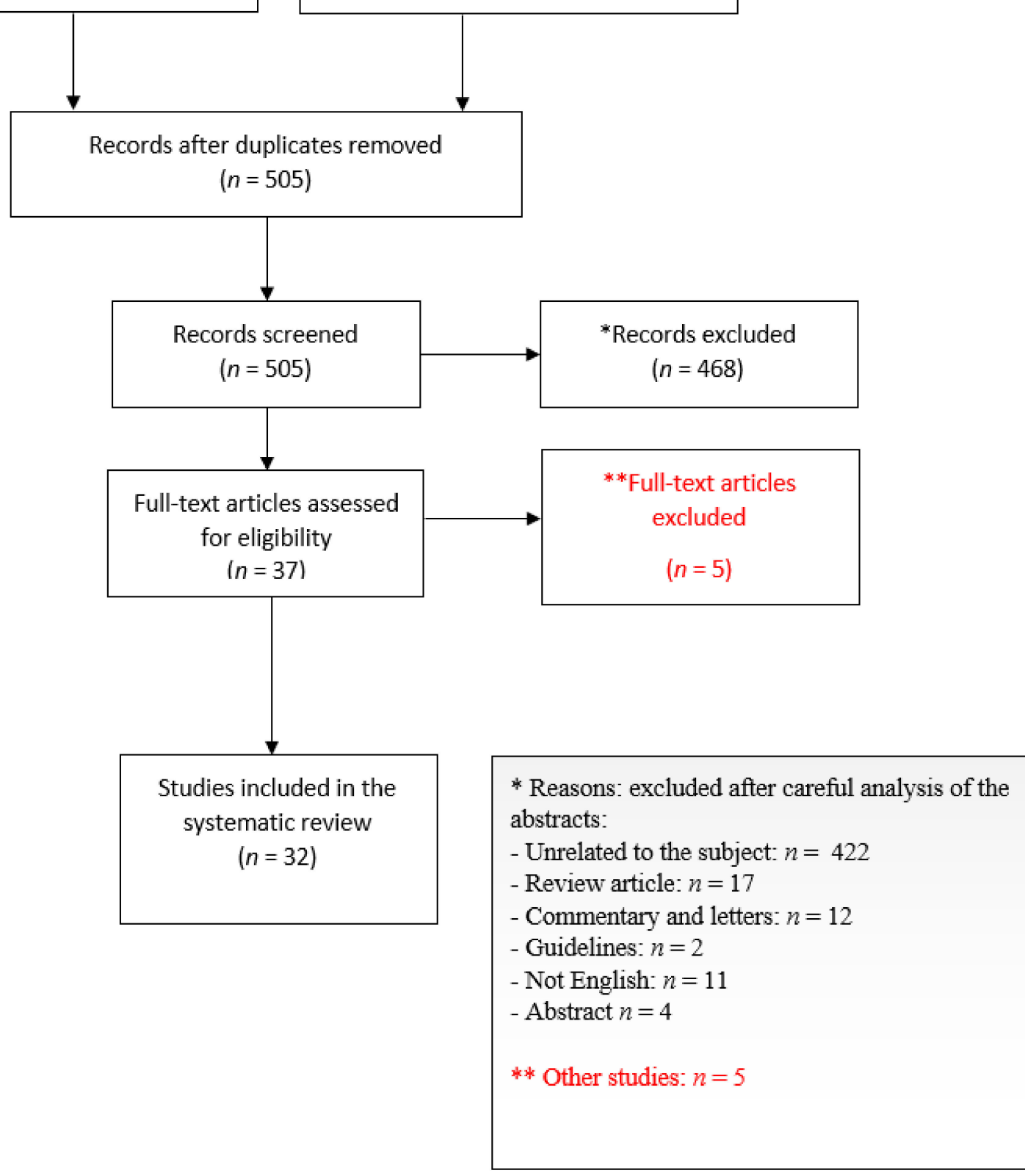

Figure 1. PRISMA flow diagram of study selection.

\section{Results}

Our literature search revealed 32 papers that were then manually inspected to determine whether they included relevant information that was then retrieved, evaluated and organized into Tables.

Table 1 summarizes spike protein mutations associated with in vitro resistance to $\mathrm{mAbs}$ targeting this protein. These mutations were used to filter the clinical case reports of treatment resistance for evidence of immune escape (Table 2). 
Table 1. Spike mutations associated with clinically-approved $\mathrm{mAb}$ resistance in vitro, sourced via the Stanford University Coronavirus Antiviral and Resistance Database (accessed online on 13 December 2021, at https: / / covdb.stanford.edu/search-drdb/). Mutations conferring resistance to both mAbs within the cocktail are underlined.

\begin{tabular}{|c|c|c|c|c|}
\hline Manufacturer & $\begin{array}{c}\text { Cocktail } \\
\text { Brand Name }\end{array}$ & $\begin{array}{l}\text { Active Ingredient } \\
\text { (Brand Name) }\end{array}$ & $\begin{array}{l}\text { Spike Mutations Associated with } \\
\text { In Vitro Resistance }\end{array}$ & Ref \\
\hline \multirow[t]{2}{*}{$\begin{array}{c}\text { Eli Lilly } \\
\text { (AbCellera/Junshi) }\end{array}$} & \multirow[t]{2}{*}{ n.a. } & $\begin{array}{c}\text { etesevimab (LyCoV016, CB6, } \\
\text { JS016, LY3832479) }\end{array}$ & $\begin{array}{c}\text { K417N/T (100 folds), } \\
\text { D420N (100 folds)F456R/A/K } \\
\text { (100 folds) } \\
\text { N460K/S/T/Y (50-100 folds) I, I472D } \\
\text { A475R/V (20-100 folds), E484K } \\
\text { N487R (100 folds), G485P, } \\
\text { Q493R/K (100 folds) }\end{array}$ & \multirow[t]{2}{*}[9,10,19]{} \\
\hline & & $\begin{array}{l}\text { bamlanivimab (LY-CoV555, } \\
\text { LY3819253) }\end{array}$ & $\begin{array}{c}\text { L452R (>100 folds, }) \\
\text { E484D/K/Q (>100 folds) } \\
\text { G485P, } \\
\text { F490S/L (100 folds }) \\
\text { Q493R/K (100 folds }) \\
\text { S494P/R (100 folds })\end{array}$ & \\
\hline \multirow{2}{*}{ Regeneron/Roche } & \multirow{2}{*}{$\begin{array}{c}\text { REGN-COV2 } \\
\text { (Ronapreve) }\end{array}$} & imdevimab (REGN10987) & $\begin{array}{c}\text { E406W (>100 folds) } \\
\text { N439K (25-100 folds) } \\
\text { N440K (28-96 folds) } \\
\text { K444L/M/N/Q/T ( }>100 \text { folds), } \\
\text { V445A ( }>100 \text { folds), } \\
\text { G446V ( }>100 \text { folds) } \\
\text { N450D (9-32 folds) } \\
\text { Q498H (17 folds) } \\
\text { P499S ( }>100 \text { folds }) \\
\text { E484K (16 folds) }\end{array}$ & \multirow{2}{*}{ [9] } \\
\hline & & casirivimab (REGN10933) & $\begin{array}{c}\text { E406W/D (50-93 folds) } \\
\text { K417E/N/R/T (25-100 folds) } \\
\text { V455T ( }>100 \text { folds) } \\
\text { Y453F (>100 folds) } \\
\text { L455F (80 folds) } \\
\text { A475R (44 folds) } \\
\text { E484K/Q (20-55 folds), F486x } \\
\text { F486K/L/R/S/V (>100 folds) } \\
\text { N487R (>100 folds) } \\
\text { Q493E/K/R (25-100 folds) }\end{array}$ & \\
\hline \multirow{2}{*}{ AstraZeneca } & \multirow{2}{*}{$\begin{array}{c}\text { AZD7442 } \\
\text { long-acting } \\
\text { antibody } \\
\text { (LAAB)(Evusheld) }\end{array}$} & $\begin{array}{c}\text { tixagevimab } \\
\text { (AZD8895/COV2-2196) }\end{array}$ & $\begin{array}{l}\text { E484K (4-11 folds) } \\
\text { S982A (3.2 folds) }\end{array}$ & \multirow{2}{*}[13,20-22]{} \\
\hline & & $\begin{array}{c}\text { cilgavimab } \\
\text { (AZD1061/COV2-2130) }\end{array}$ & E484K (3.2 folds) & \\
\hline Celltrion & - & $\begin{array}{l}\text { regdanvimab (CT-P59) } \\
\text { (Regkirona) }\end{array}$ & $\begin{array}{l}\text { L452R (35 folds) } \\
\text { E484K (8.7 folds) } \\
\text { N501Y (5.5 folds) }\end{array}$ & [23] \\
\hline GSK & - & $\begin{array}{c}\text { sotrovimab (VIR-7831, S309, } \\
\text { GSK4182136) (Xevudy) }\end{array}$ & $\begin{array}{l}\text { P337R/L/H/T (180-276 folds) } \\
\text { E340K/A/G (27-300 folds) }\end{array}$ & {$[24,25]$} \\
\hline
\end{tabular}


Table 2. Case reports of immune escape after anti-spike mAb treatment.

\begin{tabular}{|c|c|c|c|c|c|c|c|c|c|}
\hline mAb Type & $\begin{array}{c}\text { Age/Sex } \\
\text { (Identifier) }\end{array}$ & Condition (Treatments) & $\begin{array}{l}\text { Day mAb } \\
\text { Admin- } \\
\text { stered }\end{array}$ & $\begin{array}{c}\text { Other } \\
\text { Antiviral } \\
\text { Treatments }\end{array}$ & $\begin{array}{l}\text { SARS- } \\
\text { CoV-2 } \\
\text { Strain }\end{array}$ & $\begin{array}{c}\text { Spike } \\
\text { Mutations }\end{array}$ & $\begin{array}{c}\text { First } \\
\text { Detected } \\
\text { at Day }\end{array}$ & Outcome & Ref \\
\hline $\begin{array}{c}\text { REGN-CoV2 } \\
\text { cocktail }\end{array}$ & $45 / \mathrm{M}$ & $\begin{array}{l}\text { antiphospholipid syndrome } \\
\text { (steroids, rituximab, } \\
\text { ruxolitinib, IVIg, } \\
\text { cyclophosphamide) }\end{array}$ & 45 & $\begin{array}{l}\text { remdesivir } \\
(5+10+5 \text { days })\end{array}$ & n.a. & $\begin{array}{l}\text { E484K/A, } \\
\text { Y489H, } \\
\text { Q493K and } \\
\text { N501Y }\end{array}$ & 75 & death & $\begin{array}{l}\text { Choi et al. } \\
{[20]} \\
\text { Clarke et al. } \\
{[21]}\end{array}$ \\
\hline \multirow{21}{*}{$\begin{array}{l}\text { bamlanivimab } \\
\text { monotherapy } \\
\text { (700 mg iv) }\end{array}$} & $\begin{array}{l}\text { n.a./n.a. } \\
\text { (B2_11) }\end{array}$ & \multirow{9}{*}{ immunocompetent } & \multirow{9}{*}{ median 4.5} & n.a. & n.a. & E484K & $\begin{array}{l}3 \text { after } \\
\text { mAb }\end{array}$ & n.a. & \multirow{9}{*}{$\begin{array}{l}\text { Choudhary } \\
\text { et al. [22] }\end{array}$} \\
\hline & $\begin{array}{l}\text { n.a./n.a. } \\
\text { (B2_10) }\end{array}$ & & & n.a. & n.a. & S494P & $\begin{array}{l}6 \text { after } \\
\mathrm{mAb}\end{array}$ & n.a. & \\
\hline & $\begin{array}{c}\text { n.a./n.a. } \\
\text { (B2_8) }\end{array}$ & & & n.a. & n.a. & E484K & $\begin{array}{l}4 \text { after } \\
\mathrm{mAb}\end{array}$ & n.a. & \\
\hline & $\begin{array}{c}\text { n.a./n.a. } \\
\text { (B2_7) }\end{array}$ & & & n.a. & n.a. & E484K & $\begin{array}{l}6 \text { after } \\
\text { mAb }\end{array}$ & n.a. & \\
\hline & $\begin{array}{l}\text { n.a./n.a. } \\
\text { (B2_6) }\end{array}$ & & & n.a. & n.a. & $\begin{array}{c}\mathrm{S} 494 \mathrm{P}+ \\
\mathrm{E} 484 \mathrm{~K} \\
\text { (frequency } \\
<20 \% \text { ) }\end{array}$ & $\begin{array}{l}3 \text { after } \\
\text { mAb }\end{array}$ & n.a. & \\
\hline & $\begin{array}{c}\text { n.a./n.a. } \\
\text { (B2_5) }\end{array}$ & & & n.a. & n.a. & E484Q & $\begin{array}{l}4 \text { after } \\
\text { mAb }\end{array}$ & n.a. & \\
\hline & $\begin{array}{c}\text { n.a./n.a. } \\
\text { (B2_4) }\end{array}$ & & & n.a. & n.a. & E484K & $\begin{array}{l}8 \text { after } \\
\text { mAb }\end{array}$ & n.a. & \\
\hline & $\begin{array}{c}\text { n.a./n.a. } \\
\text { (B2_3) }\end{array}$ & & & n.a. & n.a. & S494P & $\begin{array}{l}6 \text { after } \\
\text { mAb }\end{array}$ & n.a. & \\
\hline & $\begin{array}{c}\text { n.a./n.a. } \\
\text { (B2_2) }\end{array}$ & & & n.a. & n.a. & E484Q & $\begin{array}{c}3 \text { after } \\
\text { mAb }\end{array}$ & n.a. & \\
\hline & $72 / \mathrm{M}$ & $\begin{array}{c}\text { chronic lymphocytic } \\
\text { leukemia and } \\
\text { hypogammaglobulinemia } \\
\text { (venetoclax and rituximab } \\
17 \text { days earlier); } \\
\text { steroids } 21-26\end{array}$ & $4(700 \mathrm{mg})$ & $\begin{array}{l}1 \text { BNT162b2 } \\
\text { dose } 20 \text { days } \\
\text { before } \\
\text { CPP day } 10\end{array}$ & Alpha & $\begin{array}{l}\text { E484K and } \\
\text { Q493R }\end{array}$ & 6 & $\begin{array}{l}\text { recovered at } \\
\text { day } 61\end{array}$ & $\begin{array}{l}\text { Truffot } \\
\text { et al. [23] }\end{array}$ \\
\hline & $55 / \mathrm{F}$ & acute myeloid leukemia & 14 & $\begin{array}{l}\text { Remdesivir } \\
\text { days 23-27 }\end{array}$ & Alpha & $\begin{array}{l}\text { E484K and } \\
\text { Q493R, } \\
\text { S494P }\end{array}$ & 21 & $\begin{array}{l}\text { negative at } \\
\text { day } 51\end{array}$ & $\begin{array}{l}\text { Lohr et al. } \\
\text { [24] }\end{array}$ \\
\hline & $70 / \mathrm{M}$ & $\begin{array}{l}\text { ANCA-associated vasculitis } \\
\text { with end-stage renal disease } \\
\text { (rituximab and } \\
\text { prednisolone) }\end{array}$ & 2 & $\begin{array}{l}3 \text { units of } \\
\text { CCP at day } 16\end{array}$ & B.1 & $\begin{array}{l}\mathrm{E} 484 \mathrm{~K} \rightarrow \\
\mathrm{E} 484 \mathrm{Q}, \\
\text { reverted to } \\
\text { E484K after } \\
\mathrm{CCP}\end{array}$ & 12 & $\begin{array}{l}\text { died of MOF } \\
\text { on day } 20\end{array}$ & \multirow{5}{*}{$\begin{array}{l}\text { Jensen et al. } \\
\text { [25] }\end{array}$} \\
\hline & $40 / \mathrm{F}$ & AIDS & 3 & $\begin{array}{l}\text { remdesivir } \\
\text { and } 2 \text { units of } \\
\text { CCP }\end{array}$ & B..1. & $\mathrm{E} 484 \mathrm{~K}$ & 10 & recovered & \\
\hline & $60 / \mathrm{M}$ & $\begin{array}{l}\text { relapsed follicular } \\
\text { lymphoma (obinutuzumab, } \\
\text { thiotepa, cytarabine, } \\
\text { etoposide) }\end{array}$ & 76 & $\begin{array}{l}2 \text { CCP units } \\
\text { on day } 57 \text { and } \\
1 \text { CCP unit on } \\
\text { day } 59\end{array}$ & B.1.177 & E484K & 87 & $\begin{array}{l}\text { recovered, } \\
\text { negative at } \\
\text { day } 103\end{array}$ & \\
\hline & $65 / \mathrm{M}$ & $\begin{array}{c}\text { heart transplant recipient } \\
\text { (about } 30 \text { years ago) } \\
\text { (cyclosporine, azathioprine, } \\
\text { prednisolone) }\end{array}$ & 2 & none & B.1.177 & $\mathrm{E} 484 \mathrm{~K}$ & 19 & $\begin{array}{l}\text { discharged at } \\
\text { day } 40 \text { after } 2 \\
\text { negative NPS }\end{array}$ & \\
\hline & $65 / \mathrm{M}$ & chronic lymphatic leukemia & 45 & $\begin{array}{l}\text { remdesivir } \\
\text { and } 3 \text { units of } \\
\text { CCP days } \\
52-62 \text {, imde- } \\
\text { vimab/casirivimab } \\
\text { about day } 70\end{array}$ & B.1.258 & $\mathrm{E} 484 \mathrm{~K}$ & 52 & $\begin{array}{l}\text { recovered, } \\
\text { negative at } \\
\text { day } 91\end{array}$ & \\
\hline & $33 / \mathrm{M}$ & $\begin{array}{l}\text { Hodgkin lymphoma } \\
\text { (untreated) }\end{array}$ & 20 & dexamethasone & B.1.362 & $\begin{array}{l}\Delta \mathrm{PF} 140 \rightarrow \\
\Delta \mathrm{PFLGVY139-} \\
144, \mathrm{G} 485 \mathrm{R} \\
\text { W258C }\end{array}$ & 45 & $\begin{array}{l}\text { hospitalized } \\
\text { for HL } \\
\text { chemother- } \\
\text { apy at end of } \\
\text { follow-up }\end{array}$ & \multirow{2}{*}{$\begin{array}{l}\text { Bronstein } \\
\text { et al. [26] }\end{array}$} \\
\hline & $68 / \mathrm{M}$ & $\begin{array}{l}\text { chronic lymphocytic } \\
\text { leukemia (FCR in 2017, } \\
\text { prednisone for AIHA, } \\
\text { venetoclax + rituximab in } \\
\text { 2019) }\end{array}$ & 10 & $\begin{array}{l}\text { CPP days } 12 \\
\text { and } 26, \mathrm{IVIg} \\
\text { day } 21, \\
\text { remdesivir } \\
\text { days } 37-41\end{array}$ & Alpha & E484Q & 22 & $\begin{array}{l}\text { discharged } \\
\text { day } 43\end{array}$ & \\
\hline & n.a. & immunocompetent & 2 & n.a. & B.1.311 & E484K & n.a. & $\begin{array}{l}\text { resolved at } \\
\text { home }\end{array}$ & $\begin{array}{c}\text { Sabin et al. } \\
\text { [27] }\end{array}$ \\
\hline & $87 / \mathrm{M}$ & immunocompetent & 2 & none & Alpha & $\begin{array}{r}\text { E484K } \\
+ \text { S494P }\end{array}$ & 6 & $\begin{array}{l}\text { discharged } \\
\text { negative at } \\
\text { day } 27\end{array}$ & \multirow{2}{*}{$\begin{array}{l}\text { Peiffer- } \\
\text { Smadja } \\
\text { et al. [28] }\end{array}$} \\
\hline & $35 / \mathrm{M}$ & immunocompetent & 2 & none & Alpha & $\mathrm{E} 484 \mathrm{~A} / \mathrm{K}$ & 6 & $\begin{array}{l}\text { discharged, } \\
\text { negative at } \\
\text { day } 38\end{array}$ & \\
\hline
\end{tabular}


Table 2. Cont.

\begin{tabular}{|c|c|c|c|c|c|c|c|c|c|}
\hline mAb Type & $\begin{array}{c}\text { Age/Sex } \\
\text { (Identifier) }\end{array}$ & Condition (Treatments) & $\begin{array}{c}\text { Day mAb } \\
\text { Admin- } \\
\text { stered }\end{array}$ & $\begin{array}{c}\text { Other } \\
\text { Antiviral } \\
\text { Treatments }\end{array}$ & $\begin{array}{l}\text { SARS- } \\
\text { CoV-2 } \\
\text { Strain }\end{array}$ & $\begin{array}{c}\text { Spike } \\
\text { Mutations }\end{array}$ & $\begin{array}{c}\text { First } \\
\text { Detected } \\
\text { at Day }\end{array}$ & Outcome & Ref \\
\hline & $61 / \mathrm{M}$ & immunocompetent & 2 & steroids & Alpha & $\mathrm{E} 484 \mathrm{~K}$ & 12 & $\begin{array}{c}\text { negative at } \\
\text { day } 8, \\
\text { hospitalized } \\
\text { for unrelated } \\
\text { reasons }\end{array}$ & \\
\hline & $97 / \mathrm{M}$ & immunocompetent & 4 & none & Alpha & E484K & 14 & $\begin{array}{l}\text { died at day } 35 \\
\text { because of } \\
\text { soft tissue } \\
\text { infection }\end{array}$ & \\
\hline & $64 / \mathrm{M}$ & heart transplant recipient & 2 & $\begin{array}{l}\text { corticosteroids } \\
\text { for } 10 \text { days }\end{array}$ & Alpha & Q493R & 26 & $\begin{array}{l}\text { discharged, } \\
\text { negative at } \\
\text { day } 48\end{array}$ & \\
\hline \multirow{13}{*}{$\begin{array}{l}\text { bamlanivimab } \\
700 \mathrm{mg}+ \\
\text { etesevimab } \\
1400 \mathrm{mg} \\
\text { cocktail }\end{array}$} & n.a. & n.a. & 2 & n.a. & n.a. & S494P & 11 & $\begin{array}{c}\text { recovered, } \\
\text { not detected } \\
\text { in samples at } \\
\text { day }\end{array}$ & $\begin{array}{l}\text { Gottlieb } \\
\text { et al. [29] }\end{array}$ \\
\hline & $73 / \mathrm{M}$ & $\begin{array}{l}\text { cholangiocarcinoma } \\
\text { (steroids) }\end{array}$ & 2 & none & Alpha & Q493R & 7 & died day 18 & $\begin{array}{c}\text { Focosi et al. } \\
\text { [30] }\end{array}$ \\
\hline & $63 / \mathrm{M}$ & $\begin{array}{l}\text { allogeneic hematopoietic } \\
\text { stem cell transplantation } \\
\text { recipient for mycosis } \\
\text { fungoides }\end{array}$ & n.a. & none & Alpha & Q493R & 15 & $\begin{array}{l}\text { discharged at } \\
\text { day } 2\end{array}$ & $\begin{array}{l}\text { Guigon } \\
\text { et al. [31] }\end{array}$ \\
\hline & n.a. & solid organ transplantation & n.a. & none & Alpha & Q493R & 7 & n.a & \multirow{5}{*}{$\begin{array}{c}\text { Vellas et al. } \\
\text { [32] }\end{array}$} \\
\hline & n.a. & solid organ transplantation & n.a. & none & Alpha & Q493R & 7 & n.a. & \\
\hline & n.a. & solid organ transplantation & n.a. & none & Alpha & Q493R & 14 & n.a. & \\
\hline & n.a. & solid organ transplantation & n.a. & none & Alpha & Q493K & 7 & n.a. & \\
\hline & n.a. & solid organ transplantation & n.a. & none & Alpha & E484K & 21 & n.a. & \\
\hline & $34 / \mathrm{F}$ & B-ALL & \multirow{5}{*}{$<5$ days } & $\begin{array}{l}2 \text { CCP units } \\
\text { days } 29-30\end{array}$ & Alpha & Q493R & n.a. & \multirow{5}{*}{$\begin{array}{l}\text { all were } \\
\text { rescued with } \\
\text { CCP }\end{array}$} & \multirow{5}{*}{$\begin{array}{l}\text { Pommeret } \\
\text { et al. [33] }\end{array}$} \\
\hline & $62 / \mathrm{F}$ & Hodgkin lymphoma & & $\begin{array}{l}1 \text { CCP unit } \\
\text { day } 26\end{array}$ & Alpha & Q493R & n.a. & & \\
\hline & $63 / \mathrm{F}$ & follicular lymphoma & & $\begin{array}{l}2 \text { CCP units } \\
\text { days } 30-31\end{array}$ & Alpha & Q493R & n.a. & & \\
\hline & $67 / \mathrm{F}$ & follicular lymphoma & & $\begin{array}{l}2 \text { CCP units } \\
\text { days } 15-16\end{array}$ & Alpha & n.a. & n.a. & & \\
\hline & $57 / \mathrm{M}$ & $\begin{array}{c}\text { chronic lymphocytic } \\
\text { leukemia }\end{array}$ & & $\begin{array}{l}2 \text { CCP units } \\
\text { days } 30-31\end{array}$ & Alpha & E484D & n.a. & & \\
\hline
\end{tabular}

Table 3 summarizes the spike mutations found in clinical cases after CCP treatment, where immune escape can be hypothesized to have occurred based on treatment failure, with the caveat that there is no definitive proof of immune escape due to heterogeneity of the (uncharacterized) polyclonal response.

Table 3. Case reports of immune escape after CCP treatment.

\begin{tabular}{|c|c|c|c|c|c|c|c|c|}
\hline $\begin{array}{c}\text { Age/Sex } \\
\text { (Identifier) }\end{array}$ & Condition & $\begin{array}{c}\mathrm{CCP} \\
\text { Schedule } \\
\text { (and Titer) }\end{array}$ & Co-Treatments & $\begin{array}{l}\text { SARS- } \\
\text { CoV-2 } \\
\text { Strain }\end{array}$ & Spike Mutations & $\begin{array}{c}\text { First } \\
\text { Detected } \\
\text { at Day }\end{array}$ & Outcome & Ref \\
\hline \multirow[b]{2}{*}{$71 / \mathrm{F}$} & \multirow{2}{*}{$\begin{array}{l}\text { chronic lymphocytic } \\
\text { leukemia and } \\
\text { iatrogenic hypogam- } \\
\text { maglobulinemia }\end{array}$} & \multirow{2}{*}{$\begin{array}{l}70(1: 60) \\
\text { and } 81 \\
(1: 160)\end{array}$} & \multirow[b]{2}{*}{ IVIG q4-6w } & \multirow[b]{2}{*}{ n.a. } & $\Delta$ PFLGVYY139-145 & 49 & \multirow{2}{*}{$\begin{array}{l}\text { negative } \\
\text { NPS since } \\
\text { day } 105\end{array}$} & \multirow{2}{*}{$\begin{array}{l}\text { Avanzato } \\
\text { et al. [34] }\end{array}$} \\
\hline & & & & & $\Delta$ LGVY141-144 & $\begin{array}{l}70 \text { (poor } \\
\text { causality) }\end{array}$ & & \\
\hline \multirow{3}{*}{$73 / \mathrm{M}$} & \multirow{3}{*}{$\begin{array}{l}\text { chimeric antigen } \\
\text { receptor T-cell } \\
\text { recipient }\end{array}$} & \multirow{3}{*}{$\begin{array}{l}\text { low titer } \\
\text { days } 2 \text { and } \\
58\end{array}$} & \multirow{3}{*}{$\begin{array}{c}\text { remdesivir days } \\
5-10,63-74 \\
\text { dexamethasone } \\
\text { days }\end{array}$} & \multirow{3}{*}{ GH } & R190K and G1124D & 13 & \multirow{3}{*}{ died day 74} & \multirow{3}{*}{$\begin{array}{l}\text { Hensley } \\
\text { et al. [35] }\end{array}$} \\
\hline & & & & & $\begin{array}{c}\Delta \mathrm{Y} 144, \mathrm{D} 215 \mathrm{G} \text {, and } \\
\text { N501T }\end{array}$ & 67 & & \\
\hline & & & & & $\Delta \mathrm{H} 146$ & 72 & & \\
\hline $70 / \mathrm{M}$ & $\begin{array}{l}\text { B-cell depletion and } \\
\text { hypogammaglobu- } \\
\text { linemia }\end{array}$ & $63,65,102$ & $\begin{array}{c}\text { remdesivir day } \\
38-48,52-62 \text { and } \\
91-101\end{array}$ & n.a. & D796H and $\Delta \mathrm{HV} 69-70$ & 57 & $\begin{array}{l}\text { died on } \\
\text { day } 102\end{array}$ & $\begin{array}{l}\text { Kemp } \\
\text { et al. [36] }\end{array}$ \\
\hline $21 / \mathrm{M}$ & $\begin{array}{c}\text { B-acute lymphoblastic } \\
\text { leukemia } \\
\text { (tisagenlecleucel) }\end{array}$ & $\begin{array}{c}78,103,110 \\
123,130 \\
137,144 \\
158,165,172\end{array}$ & $\begin{array}{c}\quad \text { remdesivir } \\
(2 \times 5 \text {-day courses })\end{array}$ & n.a. & $\begin{array}{c}3 \text { major allele variants } \\
\text { emerged between days } 0 \\
\text { and } 40 \text { with an } \\
\text { additional } 4 \text { major and } \\
7 \text { minor allele variants } \\
\text { by day } 144 \\
\text { ( } \Delta \text { LGV141-143, } \Delta \mathrm{Y} 145, \\
\Delta \mathrm{LGVY141-144,} \\
\Delta \mathrm{NL} 211-212, \mathrm{~N} 440 \mathrm{~K}, \\
\text { V483A, and E484Q) }\end{array}$ & 144 & $\begin{array}{c}\text { positive } \\
\text { NPS at end } \\
\text { of follow-up } \\
\text { (day 250) }\end{array}$ & $\begin{array}{l}\text { Truong } \\
\text { et al. [37] }\end{array}$ \\
\hline
\end{tabular}


Table 3. Cont.

\begin{tabular}{|c|c|c|c|c|c|c|c|c|}
\hline $\begin{array}{c}\text { Age/Sex } \\
\text { (Identifier) }\end{array}$ & Condition & $\begin{array}{c}\mathrm{CCP} \\
\text { Schedule } \\
\text { (and Titer) }\end{array}$ & Co-Treatments & $\begin{array}{l}\text { SARS- } \\
\text { CoV-2 } \\
\text { Strain }\end{array}$ & Spike Mutations & $\begin{array}{l}\text { First } \\
\text { Detected } \\
\text { at Day }\end{array}$ & Outcome & Ref \\
\hline $50 / \mathrm{M}$ & $\begin{array}{l}\text { kidney transplant } \\
\text { recipient (tacrolimus, } \\
\text { steroids) }\end{array}$ & 1 & tocilizumab day 2 & B.1.369 & $\begin{array}{c}\text { Q493R, } \Delta \text { AL243-244 had } \\
\sim 70 \% \text { frequency; } \\
\Delta \text { LGVY141-144, E484K } \\
\text { and Q493K had } \sim 30 \%, \\
\sim 20 \% \text { and } \sim 10 \% \\
\text { frequency }\end{array}$ & 21 & $\begin{array}{l}\text { died on } \\
\text { day } 94\end{array}$ & $\begin{array}{l}\text { Chen } \\
\text { et al. [38] }\end{array}$ \\
\hline $75 / \mathrm{M}$ & $\begin{array}{l}\text { B-CLL (FCR, } \\
\text { ibrutinib) }\end{array}$ & $\begin{array}{l}2 \text { units on } \\
\text { day } 70,2 \\
\text { units on } \\
\text { days } \\
127-128\end{array}$ & $\begin{array}{l}\text { remdesivir days } \\
24-33 \text { and } 60-64\end{array}$ & n.a. & $\begin{array}{c}\text { H49Y, } \Delta \mathrm{Y} 144, \\
\Delta \text { LLA241-243, } \\
\Delta \text { AL243-244, L242H, } \\
\text { A243P, F490S, N1178N, } \\
\text { and C1250F }\end{array}$ & 80 & $\begin{array}{l}\text { still positive } \\
\text { at end of } \\
\text { follow-up } \\
\text { (day 333) }\end{array}$ & $\begin{array}{l}\text { Monrad } \\
\text { et al. [39] }\end{array}$ \\
\hline $60 / \mathrm{M}$ & $\begin{array}{c}\text { mantle-cell } \\
\text { lymphoma and } \\
\text { associated B-cell } \\
\text { immunodeficiency } \\
\text { (rituximab, bispecific } \\
\text { mAb, } \\
\text { cyclophosphamide, } \\
\text { doxorubicin, } \\
\text { prednisone) }\end{array}$ & 31,122 & $\begin{array}{l}\text { remdesivir day } 30 \\
\text { and } 122\end{array}$ & n.a. & $\begin{array}{l}\text { mutations in ORF1a but } \\
\text { not in spike }\end{array}$ & n.a. & $\begin{array}{l}\text { still positive } \\
\text { at end of } \\
\text { follow-up } \\
\text { (day 156) }\end{array}$ & $\begin{array}{l}\text { Baang } \\
\text { et al. [40] }\end{array}$ \\
\hline $40 / \mathrm{F}$ & $\begin{array}{l}\text { diffuse large B-cell } \\
\text { lymphoma (chimeric } \\
\text { antigen receptor T } \\
\text { lymphocytes) and } \\
\text { hypogammaglobu- } \\
\text { linemia }\end{array}$ & $\begin{array}{l}\text { high-titer } \\
\text { day } 2,313\end{array}$ & $\begin{array}{l}\text { IVIG, remdesivir } \\
\text { day } 2 \text { and } 313\end{array}$ & B.1.332 & $\begin{array}{c}\Delta \mathrm{LHR} 244-246 \text { and } \\
\text { A243G }\end{array}$ & $\begin{array}{l}313 \text { (poor } \\
\text { causation) }\end{array}$ & $\begin{array}{l}\text { discharged } \\
\text { day } 324, \\
\text { cleared at } \\
\text { day } 335\end{array}$ & $\begin{array}{l}\text { Nussenblatt } \\
\text { et al. [41] }\end{array}$ \\
\hline $70 / \mathrm{F}(\mathrm{A})$ & $\begin{array}{l}\text { follicular lymphoma } \\
\text { (obinutuzumab- } \\
\text { CHOP) }\end{array}$ & $\begin{array}{l}23,34,49 \\
55,56,62 \\
65,70,73 \\
77,84,86 \\
90,94,106\end{array}$ & steroids & B.1.1.29 & L18F, R682Q, $\Delta \mathrm{Y} 144$ & 50 & $\begin{array}{l}\text { died } \\
5 \text { months } \\
\text { later }\end{array}$ & $\begin{array}{l}\text { Khatamzas } \\
\text { et al. [42] }\end{array}$ \\
\hline $70 / \mathrm{M}$ & $\begin{array}{l}\text { mantle cell lymphoma } \\
\text { (R-BAC) }\end{array}$ & 88 & $\begin{array}{c}\text { darunavir/ritonavir, } \\
\text { hydroxychloro- } \\
\text { quine, } \\
\text { methylpred- } \\
\text { nisolone, } \\
\text { tocilizumab days } 1 \\
78, \text { remdesivir days } \\
45-50 \text { and } 78-87, \\
180-184 \text { and } \\
210-214 \text {, IVIg }\end{array}$ & B.1.1 & $\begin{array}{c}\mathrm{H} 69 \mathrm{Y} / \mathrm{P}, \mathrm{V70G} \text { and } \\
\text { S982A }\end{array}$ & 238 & $\begin{array}{l}\text { died on day } \\
271 \text {, still } \\
\text { positive at } \\
\text { day } 268\end{array}$ & $\begin{array}{l}\text { Sepulcri } \\
\text { et al. [43] }\end{array}$ \\
\hline $40 / \mathrm{M}$ & $\begin{array}{c}\text { autologous } \\
\text { hematopoietic stem } \\
\text { cell transplant due to } \\
\text { a diffuse large B-cell } \\
\text { lymphoma }\end{array}$ & $\begin{array}{l}2 \text { doses on } \\
\text { days? }\end{array}$ & IVIg & B.1.128 & $\underset{\Delta \text { LGVY141-144 }}{\Delta \text { LGV141-143 }}$ & 134 & $\begin{array}{l}\text { negative } \\
\text { PCR on } \\
\text { day } 196\end{array}$ & $\begin{array}{l}\text { Mendes- } \\
\text { Correa } \\
\text { et al. [44] }\end{array}$ \\
\hline
\end{tabular}

Table 4 summarizes the data from reports of within-host clonal evolution within immunosuppressed patients not treated with nAb-based therapeutics.

Table 4. Intrahost variation in spike sequence detected in immunocompromised patients not receiving nAb-based treatments.

\begin{tabular}{|c|c|c|c|c|c|c|c|}
\hline $\begin{array}{c}\text { Age/Sex } \\
\text { (Identifier) }\end{array}$ & Condition & $\begin{array}{l}\text { Antiviral } \\
\text { Treatments }\end{array}$ & $\begin{array}{l}\text { SARS-CoV-2 } \\
\text { Strain }\end{array}$ & Spike Mutations & $\begin{array}{c}\text { First } \\
\text { Detected at } \\
\text { Day }\end{array}$ & Outcome & Ref \\
\hline $47 / \mathrm{F}$ & $\begin{array}{c}\text { diffuse large B cell lymphoma } \\
\text { (rituximab plus } \\
\text { polychemotherapy) }\end{array}$ & n.a. & B.1.1.163 & $\begin{array}{c}\text { Y453F, } \Delta \text { HV69-70, S50L, } \\
\Delta \text { LGVY141-144, T470N, and } \\
\text { D737G }\end{array}$ & 120 & $\begin{array}{c}\text { negative PCR } \\
\text { on day } 132\end{array}$ & $\underset{[7]}{\underset{\text { Bazykin et al. }}{ }}$ \\
\hline $61 / \mathrm{F}$ & $\begin{array}{l}\text { diffuse large B cell lymphoma } \\
\text { stage IVB }\end{array}$ & $\begin{array}{l}\text { remdesivir for } \\
10 \text { days, high-dose } \\
\text { steroids for } 7 \text { days }\end{array}$ & B.1.1.401 & $\begin{array}{c}\text { V3G, S50L, N87S, A222V, } \\
\Delta \text { LTTRTQLPPAYTN18-30 and } \\
\Delta \text { LGVY141-144 }\end{array}$ & 164 & $\begin{array}{l}\text { negative } P C R \\
\text { at day } 197\end{array}$ & $\begin{array}{l}\text { Borges et al. } \\
\quad[45]\end{array}$ \\
\hline $3 / F(1)$ & $\begin{array}{l}\text { B-cell acute lymphoblastic } \\
\text { leukemia (chemotherapy) }\end{array}$ & n.a. & $20 \mathrm{C}$ & silent I410I (22792:C/A) & 27 & $\begin{array}{c}\text { negative } P C R \\
\text { at day } 91\end{array}$ & \multirow{3}{*}{$\begin{array}{c}\text { Truong et al. } \\
\text { [37] }\end{array}$} \\
\hline \multirow{2}{*}{ 2/M (3) } & \multirow{2}{*}{$\begin{array}{l}\text { B-cell acute lymphoblastic } \\
\text { leukemia }\end{array}$} & \multirow{2}{*}{$\begin{array}{l}\text { remdesivir for } \\
5 \text { days }\end{array}$} & \multirow{2}{*}{$20 \mathrm{C}$} & V483A and E484Q & 139 & \multirow{2}{*}{$\begin{array}{l}\text { negative PCR } \\
\text { at day } 196\end{array}$} & \\
\hline & & & & V70P, $\Delta$ LGV141-143, N440K & 162 & & \\
\hline \multirow{4}{*}{$37 / \mathrm{F}$} & \multirow{4}{*}{$\begin{array}{l}\text { advanced HIV and } \\
\text { antiretroviral treatment failure }\end{array}$} & \multirow{4}{*}{ dexamethasone } & \multirow{4}{*}{ B.1.1.273 } & E484K & 6 & \multirow{4}{*}{$\begin{array}{l}\text { negative at } \\
\text { day } 233\end{array}$} & \multirow{4}{*}{$\underset{[46]}{\text { Karim et al. }}$} \\
\hline & & & & K417T and F490S & 71 & & \\
\hline & & & & L455F and F456L & 106 & & \\
\hline & & & & D427Y and N501Y & 190 & & \\
\hline
\end{tabular}


Table 4. Cont.

\begin{tabular}{|c|c|c|c|c|c|c|c|}
\hline $\begin{array}{c}\text { Age/Sex } \\
\text { (Identifier) }\end{array}$ & Condition & $\begin{array}{c}\text { Antiviral } \\
\text { Treatments }\end{array}$ & $\begin{array}{l}\text { SARS-CoV-2 } \\
\text { Strain }\end{array}$ & Spike Mutations & $\begin{array}{c}\text { First } \\
\text { Detected at } \\
\text { Day }\end{array}$ & Outcome & Ref \\
\hline \multirow[b]{2}{*}{$80 / \mathrm{M}$} & \multirow[b]{2}{*}{$\begin{array}{l}\text { chronic lymphocytic leukemia } \\
\text { and hypogammaglobulinemic }\end{array}$} & \multirow{2}{*}{$\begin{array}{c}\text { remdesivir days } \\
213-230, \\
\text { REGN-COV-2 day } \\
265 \\
\end{array}$} & \multirow[b]{2}{*}{ B. 52} & L179 & 58 & \multirow{2}{*}{$\begin{array}{c}\text { negative PCR } \\
\text { day } 311\end{array}$} & \multirow{2}{*}{$\begin{array}{l}\text { Kavanagh } \\
\text { Williamson } \\
\text { et al. [47] } \\
\end{array}$} \\
\hline & & & & $\begin{array}{c}\text { S255F, S477N, H655Y, D1620A, } \\
\text { \HV69-70 }\end{array}$ & 155 & & \\
\hline $40 / \mathrm{M}$ & $\begin{array}{l}\text { autologous hematopoietic } \\
\text { stem cell transplant due to a } \\
\text { diffuse large B-cell lymphoma }\end{array}$ & IVIg & B.1.128 & $\underset{\Delta \text { LGVY141-144 }}{\Delta \text { LGV141-143 }}$ & & $\begin{array}{c}\text { negative PCR } \\
\text { on day } 196\end{array}$ & $\begin{array}{l}\text { Mendes- } \\
\text { Correa et al. } \\
{[44]}\end{array}$ \\
\hline n.a./n.a. & transplant recipient & remdesivir & n.a. & $\begin{array}{c}\text { S13I, T95I, E484G, F490L, } \\
\text { ALGVY141-144, } \\
\text { DLRS244-247, and } \\
\text { DSPRRARSV680-687 }\end{array}$ & n.a. & n.a. & $\underset{[48]}{\text { Weigang et al. }}$ \\
\hline n.a./n.a. & $\begin{array}{l}18 \text { B-cell non-Hodgkin } \\
\text { lymphoma }\end{array}$ & $\begin{array}{c}44 \% \mathrm{CCP} \\
37 \% \text { remdesivir }\end{array}$ & n.a. & n.a. & requested & n.a. & Lee et al. [49] \\
\hline
\end{tabular}

Figure 2 depicts the spike RBD mutations of concern for $\mathrm{mAb}$ binding detected in vitro and in vivo and the spike mutations detected after $\mathrm{CCP}$ usage.

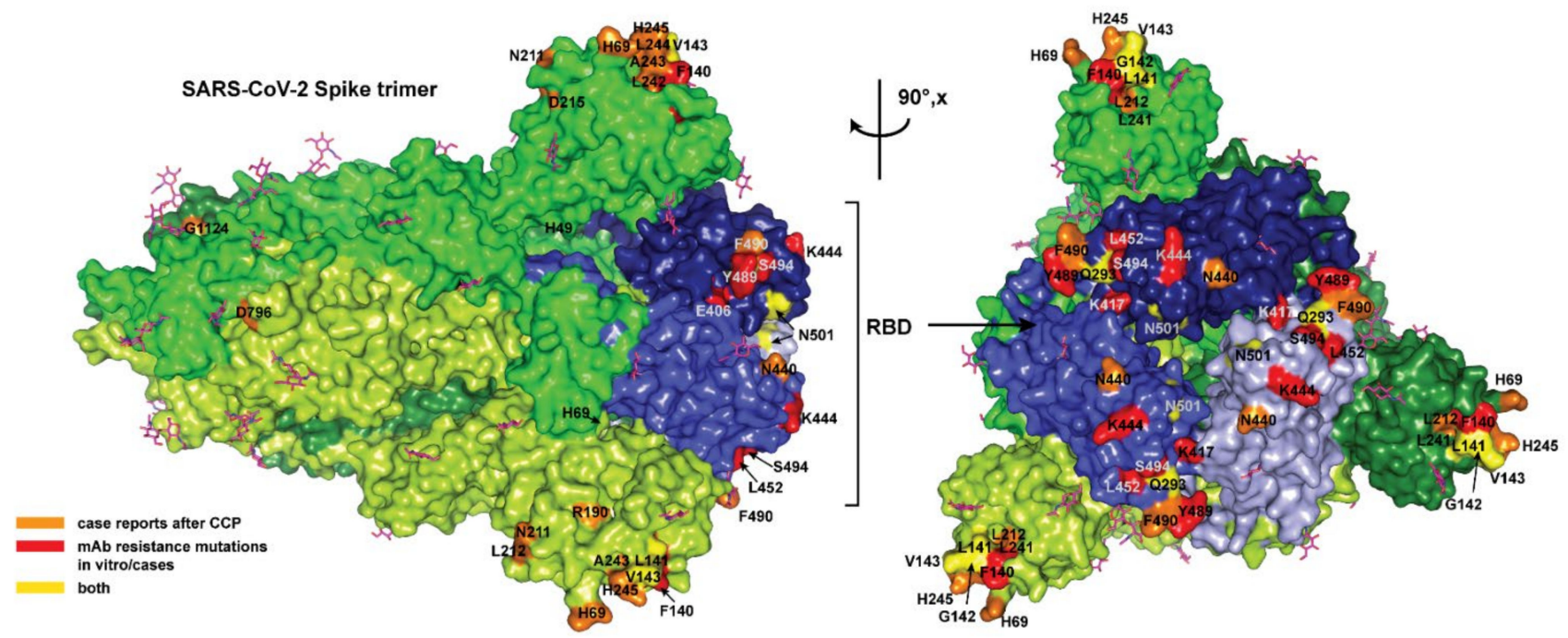

Receptor Binding Domain (319-529)

\begin{tabular}{|c|c|c|c|c|c|c|c|}
\hline \multicolumn{2}{|c|}{ Eli tilly (AbCellera/ Junshi) } & \multicolumn{2}{|c|}{ Regeneroro/Roche } & \multirow{2}{*}{$\begin{array}{c}\text { ReGN-Cov2 } \\
\text { cocictall }\end{array}$} & \multirow{2}{*}{$\begin{array}{l}\text { bamianivimab } \\
\text { monotherapy }\end{array}$} & \multirow{2}{*}{$\begin{array}{c}\text { barianinimatab } \\
\text { +etesesvimat } \\
\text { cocktail }\end{array}$} & \multirow{2}{*}{ 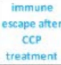 } \\
\hline eterevimas & amanivinatab & imdowimate & casirvimab & & & & \\
\hline & & E406W & E406W & & & & \\
\hline \multirow[t]{5}{*}{ KA17N/T } & & & & & & & \\
\hline & & & & & & & N440K \\
\hline & & K444 & & & & & \\
\hline & & G446 & & & & & \\
\hline & L452R & & & & & & \\
\hline \multirow{2}{*}{\multicolumn{8}{|c|}{\begin{tabular}{|l} 
N4600 \\
1472D
\end{tabular}}} \\
\hline & & & & & & & \\
\hline & & & & & & & V483A \\
\hline \multirow[t]{4}{*}{ G485P } & $\begin{array}{l}4884 \mathrm{~K} \\
6485 \\
\end{array}$ & & & E4844K/A & $\mathrm{E} 48 \mathrm{~B} 4 \mathrm{~K} / \mathrm{Q} / \mathrm{A}$ & D & \\
\hline & & & Fa86 & & & & \\
\hline & & & & $\mathrm{Y} 489 \mathrm{H}$ & & & \\
\hline & & & & & & & F4905 \\
\hline \multirow[t]{3}{*}{ Q493R/K } & Q4993R/K & & & Q4993K & Q4933R & Q493R/K & Q4993R/K \\
\hline & $5494 \mathrm{P}$ & & & & 5494P & 5494P & \\
\hline & & & & N501Y & & & 1501T \\
\hline
\end{tabular}

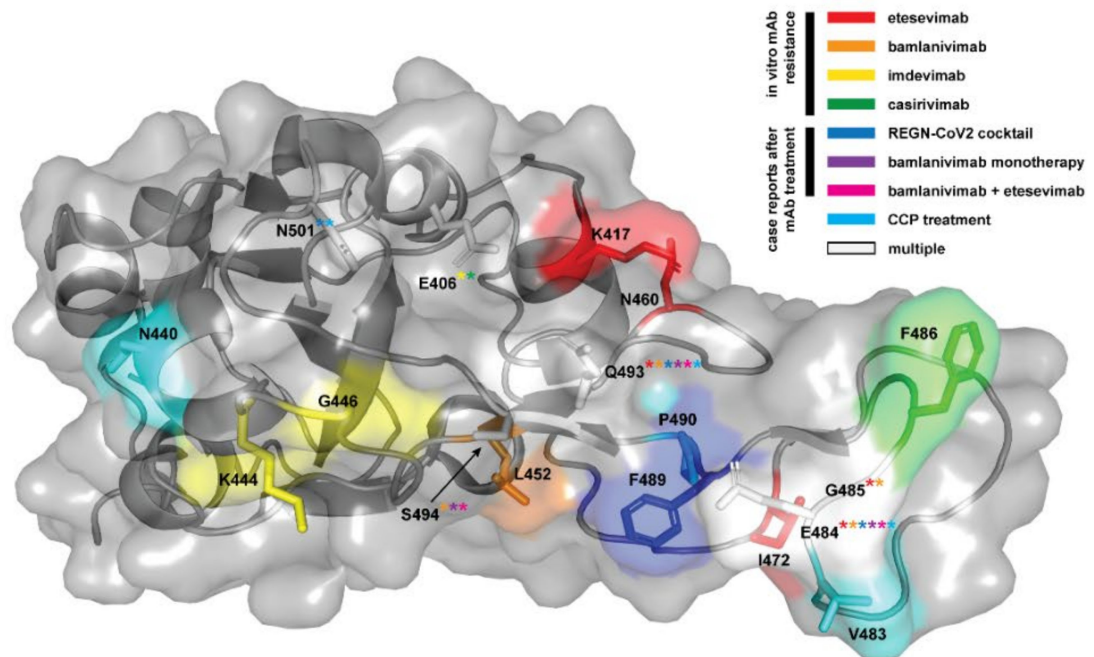

Figure 2. (Top panel) The full SARS-CoV-2 S (spike) glycoprotein homotrimer (PDBID 6VXX) [16] in the prefusion conformation is shown in surface representation, with each spike monomer colored a different shade of green. $\mathrm{N}$-linked glycosylations which were resolved in the cryo-EM map in this structure $(16 / 22$ sequons per protomer) are displayed as magenta sticks. The receptor binding domains (RBDs), in the closed state, are highlighted in 3 shades of blue corresponding to the shade of the corresponding trimer. 
Escape mutations from case reports of patients treated with CCP are highlighted in orange. Spike mutations associated with immune escape from clinically approved $\mathrm{mAb}$ treatments in vitro or from case reports are highlighted in red, while escape mutations identified in both patients who received clinically approved $\mathrm{mAb}$ treatments and CCP treatment are colored yellow. The full spike is shown oriented along the long axis (left) and rotated 90 degrees to display mutations concentrated in the RBDs. Note that mutations located on unresolved loops on the cryo-EM map of the full spike are not visualized (L18, V70, Y144, Y145, D146, R246, W258, G446, N460, I472, V483, E484, G485, F486, R682, N1178 and C1250). (Bottom panel) A table summarizing escape mutations localized to the RBD resulting from $\mathrm{mAb}$ treatments in vitro and case reports, as well as from CCP treatment. The crystal structure of single RBD domain (PBDID: 7BWJ) [17] from a more complete model (no missing loops) is displayed in surface view with the secondary structure superimposed in cartoon representation. Each escape mutation residue is highlighted by coloration according to the legend to right, and sidechains shown as sticks. In cases where a certain position corresponds to escape mutations from multiple treatments, the position is colored white and the label includes asterisks with the colors corresponding to each treatment where the escape mutation was identified. All figures were generated in PyMOL [18].

\section{Discussion}

Escape from $\mathrm{nAb}$-based therapeutics provides a crucial demonstration that these immune therapies target protective antigens, which the pathogen actively evades. Hence, the emergence of neutralizing-resistant variants in individuals receiving $\mathrm{mAb}$ and CCP provides powerful evidence for their antiviral activity. This evidence is independent of reduction in viral load, which has been reported with mAbs given early in disease but have been an inconsistent finding in randomized controlled trials (RCT) of CCP for COVID-19 [50].

Obtaining the frequencies for this phenomenon from case series is not possible due to the high risk of selection biases, which would yield unrealistically high frequencies. In contrast, RCTs with their control groups are the suggested reference. With bamlanivimab, resistance was reported in $7 \%$ of patients, regardless of dosage $(700 / 2800 / 7000 \mathrm{mg})$ versus $<1 \%$ in patients treated with placebo [22,29]. Apart from registration trials, the largest case series to date evaluated the impact of mAbs on the nasopharyngeal (NP) viral load and virus quasi-species of $\mathrm{mAb}$-treated patients using single-molecule real-time sequencing after bamlanivimab alone (4 patients), bamlanivimab/etesevimab (23 patients) and casirivimab/Imdevimab (5 patients) [32]. To date a single case of immune escape has been reported for the non-overlapping REGN-COV2 cocktail, and accordingly hamster models and clinical trials showed no emergence of variants [51]. Since mAb therapy by definition targets only a single epitope within the RBD, it is unsurprising that escape mutations observed after in vitro and in vivo selection by these mAbs were single amino acid substitutions localized almost exclusively to the RBD (Figure 2, bottom panel; Tables 1 and 2), as expected from in vitro studies with single $\mathrm{mAb}$, but largely prevented by non-overlapping mAb cocktails [52].

In contrast to $\mathrm{mAb}$ therapeutics, immune escape under $\mathrm{CCP}$ has not been investigated in RCTs. Hence, evidence exclusively stems from case series and case reports [53] and is further complicated by exposure to multiple CCP units from different donors, each one having a polyclonal response at differing titers and affinity. Unfortunately, nAb titers were very rarely determined or reported, precluding correlation between the emergence of resistance and subneutralizing CCP doses. Overall, it seems that escape variants from CCP selection have not been reported as commonly nor emerged as fast, e.g., none of the eight recipients of hematopoietic stem cell transplantation or chimeric antigen receptor T (CART) lymphocytes who were treated with CCP and tested SARS-CoV-2-positive for 2 months showed significant mutations compared to the original strain [54]. A review of the spike protein changes associated with resistance after CCP therapy reveals that most of them had in-frame amino acid deletions in a flexible region that is partially solvent exposed and forms a $\beta$ strand: plasticity may contribute to the structural permissibility of the identified deletions. The NTD is a flexible region that can be affected by immune escape via either 
insertions (causing additional glycosylation sites [12]) or recurrently deleted regions (RDR) $\Delta$ HV69-70 (RDR1), $\Delta$ LGVY141-144 and $\Delta$ D146 (RDR2), $\Delta$ I210 (RDR3) and $\Delta$ AL243-244 (RDR4) [55]: RDR1, RDR2 and RDR4 correspond to NTD loops N2, N3 and N5, whereas RDR3 falls between N4 and N5.

Deletions of amino acids from a protein structure generally result in greater structural changes than single amino acid changes, since these reduce the size of the protein and can trigger changes that propagate through the whole structure. Furthermore, the mechanism for the emergence of deletion variants appears to be very different from the single amino acid changes that are frequent from error-prone RNA replication and could involve deletions from RNA editing. Since CCP targets a large number of epitopes in the spike protein while mAbs target a single epitope, these molecular differences parallel what is expected from their respective selection pressures in the sense that escape from polyclonal preparations requires larger antigenic structural changes than escape from mAbs. In contrast to escape mutations selected for by mAb therapy, CCP selection yields point mutations throughout the spike protein. This reflects the vast antigenic surface area covered by the polyclonal antibodies within CCP. Escape mutations would be theoretically selected for on the basis of the most potent antibodies present in a particular CCP unit, which may vary markedly from donor to donor, which could explain the generally divergent evolution of SARS-CoV-2 in the presence of CCP. However, residues 141-144 and 243-244 are the sites of mutations or deletions in several cases, indicating these sites may offer effective escape from CCP derived from many donors, possibly by triggering a large-scale conformational rearrangement, as discussed above. As RBD binding antibodies are often neutralizing via ACE2 receptor occlusion, it is interesting that only $23 \%$ of CCP case studies identified the escape mutations within the RBD (Figure 2, top panel; Table 3). This suggests that antibody binding to other sites on the spike protein may have additional mechanisms of neutralization (i.e., by preventing conformational change after ACE2 engagement), or that additional antibody mediated immune responses (e.g., ADCC) are equally important as direct neutralization to the antiviral response to SARS-CoV-2.

Nothing can be inferred about the fitness of an emerging mutant in the absence of selective pressure, but it is of interest that one variant with the E484K mutant that emerged after bamlanivimab therapy was able to infect multiple household contacts [27]. In vitro, several mutants showed similar infectivity to the wild-type strain but resistance to different CCP donors [36]. In one instance of immune escape associated with CCP, a variant with D796H mutation manifested modestly reduced sensitivity to neutralization by CCP that was associated with reduced infectivity, which was only partly compensated by $\Delta$ HV69-70 [36]. Even if immune escape in registration trials has been a rare phenomenon, it should be considered that in real-world practice, mAbs targeting of the SARS-CoV-2 spike protein is being reserved for use in high-risk (immunocompromised) patients. Considering the huge size of the pandemic, the likelihood of immune escape becomes relevant, raising the possibility that rare variants with enhanced fitness could drive the next pandemic waves. Notably, several mutations have recurred in VOC and VOIs (e.g., E484K found in Beta and Gamma, E484Q found in Delta, or $\Delta$ LHR244-246 [41] found in VOI lambda), raising the possibility that such variants emerged during the treatment of patients (iatrogenic variants), but such inference will likely remain very hard to prove. E406W mutation, which causes resistance to REGN-COV-2, has never been reported in GISAID, and other E406 mutations remain exceedingly rare (worldwide, 318 cases of E406Q, 41 cases of E406D, and 2 cases each from USA for E406G, E406A, E406K, and 1 case of E406V out of $4,410,787$ sequences deposited in GISAID as of 13 December 2021). The same is true for sotrovimab resistance, with E340 and P337 mutations exceedingly rare to date (E340K in 159 sequences worldwide, P337R in 18, P337L in 195, E340A in 105, E340G in 36, P337H in 44, P337T in 90) (source: Outbreak.info). Similarly, Q493R, which causes resistance to bamlanivimab + etesevimab, had only been reported in 244 sequences and Q493K in 138 sequences, before becoming one of the hallmark mutations of VOC Omicron. L452R, which causes resistance to regdanvimab, also became prevalent first in VOI Epsilon and 
then in VOC Delta (source: Outbreak.info). Lack of fixation of those mutations facilitates the imputation that these require $\mathrm{mAb}$ selective pressure and/or effective infection control techniques in the care of those patients to prevent spill over to the general population.

Within-host variation (so-called "quasi-species swarm") is a natural phenomenon which has been reported for SARS-CoV-2 in immunocompetent patients and ultimately facilitates the persistence of infection. Among 33 patients having positive NPS PCR for an average of 18 days, Voloch et al., observed a distinguishing pattern of mutations over the course of the infection mainly driven by increasing $A \rightarrow U$ and decreasing $G \rightarrow A$ signatures, including spike mutations (V362L, T553I, H655Y, A688V, S691F, S884F, V1176F). G $\rightarrow$ A mutations are driven by the RNA-editing enzyme activities typical of innate immunity [56]. Nevertheless, several covariates can facilitate immune escape.

Immunosuppression has been postulated to be an accelerator for viral evolution. Actually, Table 4 shows that very few case reports have detailed intraclonal (within-host) evolution in patients receiving immunosuppressive treatment, and, in the absence of $\mathrm{nAb}$-based therapeutics, spike mutations rarely occurred [54].

On the other hand, co-administered small chemical antivirals can be mutagenic per se. Remdesivir has both amino and imino tautomers when pairing with RNA bases [57]. Both amino-remdesivir: $G$ and imino-remdesivir: $C$ pairs are mutagenic. It has hence been been proposed than $\mathrm{nAb}$-based therapeutics could amplify the mutations induced by remdesivir [3]. In this regard, Table 4 shows that many of the mAb- or CCP-associated mutations emerged in individuals who were or had been treated with remdesivir (but neither mAbs nor CCP), consistent with the notion that antiviral therapy could potentiate the emergence of antibody-resistant mutations.

\section{Conclusions}

In summary, our survey of the available mutational data show that escape variants associated with $\mathrm{mAb}$ and $\mathrm{CCP}$ therapy manifest different type of mutations. For mAbs, most mutations are single amino acid replacements in the RBD domain, while most variants eliciited in patients treated with CCP exhibited amino acid deletions. In fact, it is noteworthy that RBD mutations were relatively rare in CCP escape variants. Although the numbers are relatively small, which suggests caution in making generalizations, this dichotomy in geography of $\mathrm{mAb}$ and CCP mutations could reflect the fact that mAbs target a single epitope where the $\mathrm{mAb}$-antigen interaction can be significantly altered by single amino acid changes while CCP targets many epitopes and has several mechanisms of action, such that evading polyclonal antibody immunity is likely to require much larger spike protein structural changes. Despite the relatively small set of variants for which there is molecular data available, the large variation of molecular solutions that allow SARS-CoV-2 to escape antibody-mediated protection is striking and suggest the need for continued vigilance in genomic surveillance, especially in cases refractory to therapy.

Author Contributions: D.F. conceived the manuscript; F.M. analyzed the literature; S.M. provided Figure 2 and revised the final version; A.C. revised the final version, M.F. provided Figure 1 and revised the final version. All authors have read and agreed to the published version of the manuscript.

Funding: This research received no external funding.

Data Availability Statement: The data presented in this study are openly available in PubMed, medRxiv and bioRxiv.

Conflicts of Interest: We declare we do not have any conflict of interest related to this manuscript.

\section{Abbreviations}

$\mathrm{nAb}$ neutralizing antibodies;

CCP COVID-19-convalescent plasma;

PSM propensity score-matched

RCT randomized controlled trials 


\section{References}

1. $\quad$ Egeren, D.V.; Novokhodko, A.; Stoddard, M.; Tran, U.; Zetter, B.; Rogers, M.; Pentelute, B.L.; Carlson, J.M.; Hixon, M.S.; Joseph-McCarthy, D.; et al. Risk of evolutionary escape from neutralizing antibodies targeting SARS-CoV-2 spike protein. medRxiv 2020. [CrossRef]

2. Landis, J.; Moorad, R.; Pluta, L.J.; Caro-Vegas, C.; McNamara, R.P.; Eason, A.B.; Bailey, A.; Villamor, F.C.S.; Juarez, A.; Wong, J.P.; et al. Intra-host evolution provides for continuous emergence of SARS-CoV-2 variants. medRxiv 2021. [CrossRef]

3. Colson, P.; Devaux, C.A.; Lagier, J.C.; Gautret, P.; Raoult, D. A Possible Role of Remdesivir and Plasma Therapy in the Selective Sweep and Emergence of New SARS-CoV-2 Variants. J. Clin. Med. 2021, 10, 3276. [CrossRef] [PubMed]

4. $\quad$ Kabinger, F.; Stiller, C.; Schmitzová, J.; Dienemann, C.; Hillen, H.S.; Höbartner, C.; Cramer, P. Mechanism of molnupiravir-induced SARS-CoV-2 mutagenesis. Nat. Struct. Mol. Biol. 2021, 28, 740-746. [CrossRef]

5. Starr, T.N.; Greaney, A.J.; Hilton, S.K.; Ellis, D.; Crawford, K.H.D.; Dingens, A.S.; Navarro, M.J.; Bowen, J.E.; Tortorici, M.A.; Walls, A.C.; et al. Deep Mutational Scanning of SARS-CoV-2 Receptor Binding Domain Reveals Constraints on Folding and ACE2 Binding. Cell 2020, 182, 1295-1310.e20. [CrossRef] [PubMed]

6. Greaney, A.J.; Starr, T.N.; Gilchuk, P.; Zost, S.J.; Binshtein, E.; Loes, A.N.; Hilton, S.K.; Huddleston, J.; Eguia, R.; Crawford, K.H.D.; et al. Complete Mapping of Mutations to the SARS-CoV-2 Spike Receptor-Binding Domain that Escape Antibody Recognition. Cell Host Microbe 2021, 29, 44-57.e9. [CrossRef] [PubMed]

7. Bazykin, G.; Stanevich, O.; Danilenko, D.; Fadeev, A.; Komissarova, K.; Ivanova, A.; Sergeeva, M.; Safina, K.; Nabieva, E.; Klink, G.; et al. Emergence of Y453F and $\Delta 699-70 H V$ Mutations in a Lymphoma Patient with Long-Term COVID-19. Available online: https:/ / virological.org/t/emergence-of-y453f-and-69-70hv-mutations-in-a-lymphoma-patient-with-long-term-covid19/580 (accessed on 14 December 2021).

8. Javanmardi, K.; Chou, C.-W.; Terrace, C.; Annapareddy, A.; Kaoud, T.S.; Guo, Q.; Lutgens, J.; Zorkic, H.; Horton, A.P.; Gardner E.C.; et al. Rapid characterization of spike variants via mammalian cell surface display. bioRxiv 2021. [CrossRef] [PubMed]

9. Starr, T.N.; Greaney, A.J.; Addetia, A.; Hannon, W.W.; Choudhary, M.C.; Dingens, A.S.; Li, J.Z.; Bloom, J.D. Prospective mapping of viral mutations that escape antibodies used to treat COVID-19. Science 2021, 371, 850-854. [CrossRef]

10. Starr, T.N.; Greaney, A.J.; Dingens, A.S.; Bloom, J.D. Complete map of SARS-CoV-2 RBD mutations that escape the monoclonal antibody LY-CoV555 and its cocktail with LY-CoV016. Cell Rep. Med. 2021, 20, 2. [CrossRef]

11. Garrett, M.E.; Galloway, J.; Chu, H.Y.; Itell, H.L.; Stoddard, C.I.; Wolf, C.R.; Logue, J.K.; McDonald, D.; Matsen, F.A.; Overbaugh, J. High resolution profiling of pathways of escape for SARS-CoV-2 spike-binding antibodies. bioRxiv 2020. [CrossRef] [PubMed]

12. Andreano, E.; Piccini, G.; Licastro, D.; Casalino, L.; Johnson, N.V.; Paciello, I.; Dal Monego, S.; Pantano, E.; Manganaro, N.; Manenti, A.; et al. SARS-CoV-2 escape in vitro from a highly neutralizing COVID-19 convalescent plasma. Proc. Natl. Acad. Sci. USA 2021, 118, e2103154118. [CrossRef] [PubMed]

13. Wang, Z.; Schmidt, F.; Weisblum, Y.; Muecksch, F.; Barnes, C.O.; Finkin, S.; Schaefer-Babajew, D.; Cipolla, M.; Gaebler, C.; Lieberman, J.A.; et al. mRNA Vaccine-Elicited Antibodies to SARS-CoV-2 and Circulating Variants. Available online: https: / / www.biorxiv.org/content/biorxiv/early/2021/01/19/2021.01.15.426911.full.pdf (accessed on 14 December 2021).

14. Casadevall, A.; Henderson, J.; Joyner, M.; Pirofski, L.-A. SARS-Cov2 variants and convalescent plasma: Reality, fallacies, and opportunities. J. Clin. Investig. 2021, 131, e148832. [CrossRef] [PubMed]

15. Valesano, A.L.; Rumfelt, K.E.; Dimcheff, D.E.; Blair, C.N.; Fitzsimmons, W.J.; Petrie, J.G.; Martin, E.T.; Lauring, A.S. Temporal dynamics of SARS-CoV-2 mutation accumulation within and across infected hosts. PLoS Pathog. 2021, 17, e1009499. [CrossRef] [PubMed]

16. Walls, A.C.; Park, Y.J.; Tortorici, M.A.; Wall, A.; McGuire, A.T.; Veesler, D. Structure, Function, and Antigenicity of the SARS-CoV-2 Spike Glycoprotein. Cell 2020, 181, 281-292.e6. [CrossRef] [PubMed]

17. Ju, B.; Zhang, Q.; Ge, J.; Wang, R.; Sun, J.; Ge, X.; Yu, J.; Shan, S.; Zhou, B.; Song, S.; et al. Human neutralizing antibodies elicited by SARS-CoV-2 infection. Nature 2020, 584, 115-119. [CrossRef] [PubMed]

18. The PyMOL Molecular Graphics System, Version 2.4.1. Schrödinger, LLC. Available online: https://pymol.org/2/ (accessed on 21 December 2021).

19. Wang, P.; Nair, M.S.; Lihong, L.; Iketani, S.; Luo, Y.; Guo, Y.; Wang, M.; Yu, J.; Zhang, B.; Kwong, P.D.; et al. Antibody resistance of SARS-CoV-2 variants B.1.351 and B.1.1.7. Nature 2021, 593, 130-135. [CrossRef]

20. Choi, B.; Choudhary, M.C.; Regan, J.; Sparks, J.A.; Padera, R.F.; Qiu, X.; Solomon, I.H.; Kuo, H.-H.; Boucau, J.; Bowman, K.; et al. Persistence and Evolution of SARS-CoV-2 in an Immunocompromised Host. N. Engl. J. Med. 2020, 383, 2291-2293. [CrossRef]

21. Clark, S.A.; Clark, L.E.; Pan, J.; Coscia, A.; McKay, L.G.A.; Shankar, S.; Johnson, R.I.; Brusic, V.; Choudhary, M.C.; Regan, J.; et al. SARS-CoV-2 evolution in an immunocompromised host reveals shared neutralization escape mechanisms. Cell 2021, 184, 2605-2617.e18. [CrossRef] [PubMed]

22. Choudhary, M.C.; Chew, K.W.; Deo, R.; Flynn, J.P.; Regan, J.; Crain, C.R.; Moser, C.; Hughes, M.; Ritz, J.; Ribeiro, R.M.; et al. Emergence of SARS-CoV-2 Resistance with Monoclonal Antibody Therapy. medRxiv 2021. [CrossRef]

23. Truffot, A.; Andreani, J.; Le Marechal, M.; Caporossi, A.; Epaulard, O.; Poignard, P.; Sylvie, L. SARS-CoV-2 Variants in Immunocompromised Patient Given Antibody Monotherapy. Emerg. Infect. Dis. 2021, 27, 2725-2728. [CrossRef] [PubMed]

24. Lohr, B.; Niemann, D.; Verheyen, J. Bamlanivimab treatment leads to rapid selection of immune escape variant carrying E484K mutation in a B.1.1.7 infected and immunosuppressed patient. Clin. Infect. Dis. Off. Publ. Infect. Dis. Soc. Am. 2021, 73, $2144-2145$. [CrossRef] [PubMed] 
25. Jensen, B.; Luebke, N.; Feldt, T.; Keitel, V.; Brandenburger, T.; Kindgen-Milles, D.; Lutterbeck, M.; Freise, N.F.; Schoeler, D.; Haas, R.; et al. Emergence of the E484K mutation in SARS-COV-2-infected immunocompromised patients treated with bamlanivimab in Germany. Lancet Reg. Eur. 2021, 8, 100164. [CrossRef]

26. Bronstein, Y.; Adler, A.; Katash, H.; Halutz, O.; Herishanu, Y.; Levytskyi, K. Evolution of spike mutations following antibody treatment in two immunocompromised patients with persistent COVID-19 infection. J. Med. Virol. 2021. [CrossRef]

27. Sabin, A.P.; Richmond, C.S.; Kenny, P.A. Acquisition and onward transmission of a SARS-CoV-2 E484K variant among household contacts of a bamlanivimab-treated patient. medRxiv 2021. [CrossRef]

28. Peiffer-Smadja, N.; Bridier-Nahmias, A.; Ferré, V.M.; Charpentier, C.; Garé, M.; Rioux, C.; Allemand, A.; Lavallée, P.; Ghosn, J.; Kramer, L.; et al. Emergence of E484K Mutation Following Bamlanivimab Monotherapy among High-Risk Patients Infected with the Alpha Variant of SARS-CoV-2. Viruses 2021, 13, 1642. [CrossRef] [PubMed]

29. Gottlieb, R.L.; Nirula, A.; Chen, P.; Boscia, J.; Heller, B.; Morris, J.; Huhn, G.; Cardona, J.; Mocherla, B.; Stosor, V.; et al. Effect of Bamlanivimab as Monotherapy or in Combination with Etesevimab on Viral Load in Patients with Mild to Moderate COVID-19: A Randomized Clinical Trial. JAMA 2021, 325, 632-644. [CrossRef] [PubMed]

30. Focosi, D.; Novazzi, F.; Genoni, A.; Dentali, F.; Dalla Gasperina, D.; Baj, A.; Maggi, F. Emergence of SARS-COV-2 Spike Protein Escape Mutation Q493R after Treatment for COVID-19. Emerg Infect. Dis. 2021, 27, 2728-2731. [CrossRef] [PubMed]

31. Guigon, A.; Faure, E.; Lemaire, C.; Chopin, M.; Tinez, C.; Assaf, A.; Lazrek, M.; Hober, D.; Bocket, L.; Engelmann, I.; et al. Emergence of Q493R mutation in SARS-CoV-2 spike protein during bamlanivimab/etesevimab treatment and resistance to viral clearance. J. Infect. 2021. [CrossRef]

32. Vellas, C.; Del Bello, A.; Alexa, D.; Steinmeyer, Z.; Tribaudeau, L.; Ranger, N.; Jeanne, N.; Martin-Blondel, G.; Delobel, P.; Kamar, N.; et al. Influence of treatment with neutralizing monoclonal antibodies on the SARS-CoV-2 nasopharyngeal load and quasispecies. Clin. Microb Infect. 2021, 28, 139.e5-139.e8. [CrossRef] [PubMed]

33. Pommeret, F.; Colomba, J.; Bigenwald, C.; Laparra, A.; Bockel, S.; Bayle, A.; Michot, J.M.; Hueso, T.; Albiges, L.; Tiberghien, P.; et al. Bamlanivimab + etesevimab therapy induces SARS-CoV-2 immune escape mutations and secondary clinical deterioration in COVID-19 patients with B-cell malignancies. Ann. Oncol. 2021, 32, 1445-1447. [CrossRef]

34. Avanzato, V.A.; Matson, M.J.; Seifert, S.N.; Pryce, R.; Williamson, B.N.; Anzick, S.L.; Barbian, K.; Judson, S.D.; Fischer, E.R.; Martens, C.; et al. Case Study: Prolonged Infectious SARS-CoV-2 Shedding from an Asymptomatic Immunocompromised Individual with Cancer. Cell 2020, 183, 1901-1912.e9. [CrossRef]

35. Hensley, M.K.; Bain, W.G.; Jacobs, J.; Nambulli, S.; Parikh, U.; Cillo, A.; Staines, B.; Heaps, A.; Sobolewski, M.D.; Rennick, L.J.; et al. Intractable COVID-19 and Prolonged SARS-CoV-2 Replication in a CAR-T-cell Therapy Recipient: A Case Study. Clin. Infect. Dis. Off. Publ. Infect. Dis. Soc. Am. 2021, 73, e815-e821. [CrossRef] [PubMed]

36. Kemp, S.A.; Collier, D.A.; Datir, R.; Gayed, S.; Jahun, A.; Hosmillo, M.; Ferreira, I.A.; Rees-Spear, C.; Mlcochova, P.; Lumb, I.U.; et al. SARS-CoV-2 evolution during treatment of chronic infection. Nature 2021, 592, 277-282. [CrossRef] [PubMed]

37. Truong, T.T.; Ryutov, A.; Pandey, U.; Yee, R.; Goldberg, L.; Bhojwani, D.; Aguayo-Hiraldo, P.; Pinsky, B.A.; Pekosz, A.; Shen, L.; et al. Persistent SARS-CoV-2 infection and increasing viral variants in children and young adults with impaired humoral immunity. EBioMedicine 2021, 67, 103355. [CrossRef]

38. Chen, L.; Zody, M.C.; Mediavilla, J.R.; Cunningham, M.H.; Composto, K.; Chow, K.F.; Kordalewska, M.; Corvelo, A.; Oschwald, D.M.; Fennessey, S.; et al. Emergence of multiple SARS-CoV-2 antibody escape variants in an immunocompromised host undergoing convalescent plasma treatment. mSphere 2021, 6, e0048021. [CrossRef] [PubMed]

39. Monrad, I.; Sahlertz, S.R.; Nielsen, S.S.F.; Pedersen, L.; Petersen, M.S.; Kobel, C.M.; Tarpgaard, I.H.; Storgaard, M.; Mortensen, K.L.; Schleimann, M.H.; et al. Persistent Severe Acute Respiratory Syndrome Coronavirus 2 Infection in Immunocompromised Host Displaying Treatment Induced Viral Evolution. Open Forum Infect. Dis. 2021, 8, ofab295. [CrossRef] [PubMed]

40. Baang, J.H.; Smith, C.; Mirabelli, C.; Valesano, A.L.; Manthei, D.M.; Bachman, M.A.; Wobus, C.E.; Adams, M.; Washer, L.; Martin, E.T.; et al. Prolonged Severe Acute Respiratory Syndrome Coronavirus 2 Replication in an Immunocompromised Patient. J. Infect. Dis 2021, 223, 23-27. [CrossRef] [PubMed]

41. Nussenblatt, V.; Roder, A.; Das, S.; de Wit, E.; Youn, J.-H.; Banakis, S.; Muchegian, A.; Mederos, C.; Wang, W.; Chung, M.; et al. Year-long COVID-19 infection reveals within-host evolution of SARS-CoV-2 in a patient with B cell depletion. medRxiv 2021. [CrossRef]

42. Khatamzas, E.; Rehn, A.; Muenchhoff, M.; Hellmuth, J.; Gaitzsch, E.; Weiglein, T.; Georgi, E.; Scherer, C.; Stecher, S.; Weigert, O.; et al. Emergence of multiple SARS-CoV-2 mutations in an immunocompromised host. medRxiv 2021. [CrossRef]

43. Sepulcri, C.; Dentone, C.; Mikulska, M.; Bruzzone, B.; Lai, A.; Fenoglio, D.; Bozzano, F.; Bergna, A.; Parodi, A.; Altosole, T.; et al. The longest persistence of viable SARS-CoV-2 with recurrence of viremia and relapsing symptomatic COVID-19 in an immunocompromised patient-A case study. Open Forum Infect. Dis. 2021, 8, ofab217. [CrossRef] [PubMed]

44. Mendes-Correa, M.C.; Ghilardi, F.; Salomao, M.C.; Villas-Boas, L.S.; Vincente de Paula, A.; Tozetto-Mendoza, T.R.; Freire, W.; Sales, F.C.; Romano, C.M.; Claro, I.M.; et al. SARS-CoV-2 shedding, infectivity and evolution in an immunocompromised adult patient. medRxiv 2021. [CrossRef]

45. Borges, V.; Isidro, J.; Cunha, M.; Cochicho, D.; Martins, L.; Banha, L.; Figueiredo, M.; Rebelo, L.; Trindade, M.; Duarte, S.; et al. Long-term evolution of SARS-CoV-2 in an immunocompromised patient with non-Hodgkin lymphoma. mSphere 2021, 6, e0024421. [CrossRef] [PubMed] 
46. Karim, F.; Moosa, M.Y.; Gosnell, B.; Sandile, C.; Giandhari, J.; Pillay, S.; Tegally, H.; Wilkinson, E.; San, E.J.; Msomi, N.; et al. Persistent SARS-CoV-2 infection and intra-host evolution in association with advanced HIV infection. medRxiv 2021. [CrossRef]

47. Kavanagh Williamson, M.; Hamilton, F.; Hutchings, S.; Pymont, H.M.; Hackett, M.; Arnold, D.; Maskell, N.; MacGowan, A.P.; Albur, m.; Jenkins, M.; et al. Chronic SARS-CoV-2 infection and viral evolution in a hypogammaglobulinaemic individual. medRxiv 2021. [CrossRef]

48. Weigang, S.; Fuchs, J.; Zimmer, G.; Schnepf, D.; Kern, L.; Beer, J.; Luxenburger, H.; Ankerhold, J.; Falcone, V.; Kemming, J.; et al. Within-host evolution of SARS-CoV-2 in an immunosuppressed COVID-19 patient: A source of immune escape variants. medRxiv 2021. [CrossRef] [PubMed]

49. Lee, C.Y.; Shah, M.K.; Hoyos, D.; Solovyov, A.; Douglas, M.; Taur, Y.; Maslak, P.G.; Babady, N.E.; Greenbaum, B.; Kamboj, M.; et al Prolonged SARS-CoV-2 infection in patients with lymphoid malignancies. medRxiv 2021. [CrossRef] [PubMed]

50. Focosi, D.; Franchini, M.; Pirofski, L.A.; Maggi, F.; Casadevall, A. Is SARS-CoV-2 viral clearance in nasopharyngal swabs an appropriate surrogate marker for clinical efficacy of neutralizing antibody-based therapeutics? Rev. Med. Virol. 2021, e2314. [CrossRef]

51. Copin, R.; Baum, A.; Wloga, E.; Pascal, K.E.; Giordano, S.; Fulton, B.O.; Zhou, A.; Negron, N.; Lanza, K.; Chan, N.; et al. REGEN-COV protects against viral escape in preclinical and human studies. bioRxiv 2021, preprint. [CrossRef]

52. Baum, A.; Fulton, B.O.; Wloga, E.; Copin, R.; Pascal, K.E.; Russo, V.; Giordano, S.; Lanza, K.; Negron, N.; Ni, M.; et al. Antibody cocktail to SARS-CoV-2 spike protein prevents rapid mutational escape seen with individual antibodies. Science 2020, 369, 1014-1018. [CrossRef]

53. Harvey, W.T.; Carabelli, A.M.; Jackson, B.; Gupta, R.K.; Thomson, E.C.; Harrison, E.M.; Ludden, C.; Reeve, R.; Rambaut, A.; Peacock, S.J.; et al. SARS-CoV-2 variants, spike mutations and immune escape. Nat. Rev. Microbiol. 2021, 19, 409-424. [CrossRef] [PubMed]

54. Aydillo, T.; Gonzalez-Reiche, A.S.; Aslam, S.; van de Guchte, A.; Khan, Z.; Obla, A.; Dutta, J.; van Bakel, H.; Aberg, J.; García-Sastre, A.; et al. Shedding of Viable SARS-CoV-2 after Immunosuppressive Therapy for Cancer. N. Engl. J. Med. 2020, 383, 2586-2588. [CrossRef]

55. McCarthy, K.R.; Rennick, L.J.; Nambulli, S.; Robinson-McCarthy, L.R.; Bain, W.G.; Haidar, G.; Duprex, W.P. Recurrent deletions in the SARS-CoV-2 spike glycoprotein drive antibody escape. Science 2021, 371, 1139-1142. [CrossRef] [PubMed]

56. Voloch, C.M.; da Silva Francisco, R., Jr.; de Almeida, L.G.P.; Brustolini, O.J.; Cardoso, C.C.; Gerber, A.L.; Guimarães, A.P.d.C.; Leitão, I.d.C.; Mariani, D.; Ota, V.A.; et al. Intra-host evolution during SARS-CoV-2 prolonged infection. Virus Evol. 2021, 7, veab078. [CrossRef] [PubMed]

57. Singh, V.; Fedeles, B.I.; Essigmann, J.M. Role of tautomerism in RNA biochemistry. RNA 2015, 21, 1-13. [CrossRef] [PubMed] 